\title{
HISTORICAL AGRICULTURAL LANDSCAPES: MAPPING SEASONAL CONDITIONS FOR SUSTAINABLE TOURISM
}

\author{
A. Rolando, A. Scandiffio \\ ${ }^{1}$ Politecnico di Milano, Department of Architecture and Urban Studies, Milan, Italy \\ andrea.rolando@polimi.it \\ alessandro.scandiffio@polimi.it
}

KEY WORDS: Seasonal landscape, paddy-rice, mapping, historical landscape, GIS, Sentinel 2, sustainable tourism

\begin{abstract}
:
The current research aims at exploring the relationships between historical agricultural landscapes and sustainable tourism, by combining the potential of aerial and ground observation methods, that are able to detect the seasonal landscape changes. These phenomena are strongly interlaced with the annual cycle of plants, which have many implications for ecological processes, agriculture, health, tourism, regional/urban planning and economy. In many countries, similar phenomena as the timing of springblooming or the timing of autumn coloring foliage are of great visual value and can be of touristic interest, so to enhance the overall attractiveness of a territory. The research analyzes the case study of the historical agricultural landscape, localized in the in-between territories Turin and Milan, which is characterized by large portions of paddy-rice fields, which assume different aesthetical configurations over the year. This landscape, made up of an articulated system of waterways that support large portions of rice cultivation, protected natural areas, historical farmhouses, urban settlements, is the result of a long process of interaction between natural elements and human activities. Remote sensing and ground observations can play an important role in a high-accuracy mapping of the seasonal conditions of this kind of landscape. The flooding of paddy-rice fields determines a high scenic value of large portions of the rural landscape, that can be detected through remote sensing. The specificity of rice cultivation is that plants grow on flooded soils. Such a temporary condition of the landscape can become an unexpected tourist destination. From the methodological point of view, the research combines the potential of time series of satellite high-resolution imagery, for computing vegetation indexes (i.e. NDVI, NDWI etc.), and ground observations, through GIS mapping tools. This interpretation tools are useful to trace a network of slow scenic routes that allow perceiving such temporary landscape conditions and that support a territorial strategy aiming at a sustainable development of these fragile territories.
\end{abstract}

\section{INTRODUCTION}

The current research aims at integrating analysis techniques based on Remote Sensing (RS) and Geographic Information System (GIS) to create a platform where the seasonal changes of historical agricultural landscape can be mapped. Since 1972, cultural landscapes have been recognized and listed by UNESCO, through the World Heritage Convention, which has ensured the identification, protection, conservation and transmission to future generations of the cultural and natural heritage of outstanding universal value. A wider meaning of the word landscape was given by the European Landscape Convention which considers all European territory as landscape; it concerns both outstanding landscapes, everyday landscapes and degraded landscapes, as a result of a long process of interaction of natural and human factors (Council of Europe, 2000). Particularly the research refers to historical agricultural landscapes, that have been shaped over the centuries, according to the evolution of the agricultural techniques; they are fragile but vital resources for local economies, and they can be further enhanced in terms of sustainable tourism as a base for economic and spatial development. In fact, in different periods of the year, agricultural landscapes also assume different aesthetical configurations, so to become unconventional tourist destinations. The seasonal landscape changes are strongly interlaced with the annual cycle of plants and with human activities, which intervene in their spatial organization. Many factors, both natural and anthropic, can influence the timing of these changeable phenomena (temperature, water availability, weather conditions, cultivation type, cultivation schedule etc.). In this framework, RS and GIS can play a key role in high- accuracy tracking and mapping of seasonal landscape changes. In the field of agricultural landscape mapping, vegetation indices such as NDVI (Normalized Difference Vegetation Index), are sensitive indicators for monitoring the crop status, but they can be also exploited for mapping the scenic conditions of large portions of rural landscapes (Xiao et al., 2002) (Xiao et. al. 2006).

\section{STUDY AREA: THE HISTORICAL AGRICULTURAL LANDSCAPE IN-BETWEEN TURIN AND MILAN}

The research has been applied to a portion of the historical agricultural landscape which is localized in-between Turin and Milan. The research refers to a flat landscape, surrounded by the Alps on the north and on the west. It is mostly characterized by large portions of paddy-rice fields, which assume different aesthetical configurations over the year. The specificity of rice cultivation is that plants grow on flooded soils. Particularly the flooding stage, over the spring season (April, May and June), is the most attractive in terms of beauty and aesthetic experience of the landscape. During the seeding stage, the fields change their aspect and assume the character of a so called squared sea, bordered by rows of trees and minor roads that cross the agricultural fields (Fig.2). As well as it occurs for the phenomenon of spring-blooming or for the autumn colouring, the flooding of paddy-rice fields can become the final destination for inhabitants and tourists who aim at experiencing this landscape (Chen, et al. 2016). This area, which includes portions of the provinces of Biella, Novara and Vercelli, in the Piedmont Region, northwest of Italy, is very large and it is one 
of most productive in Europe. To have an idea of the size, the study area can be framed by a rectangle $60 \mathrm{~km}$ x $50 \mathrm{~km}$ (Fig.1).

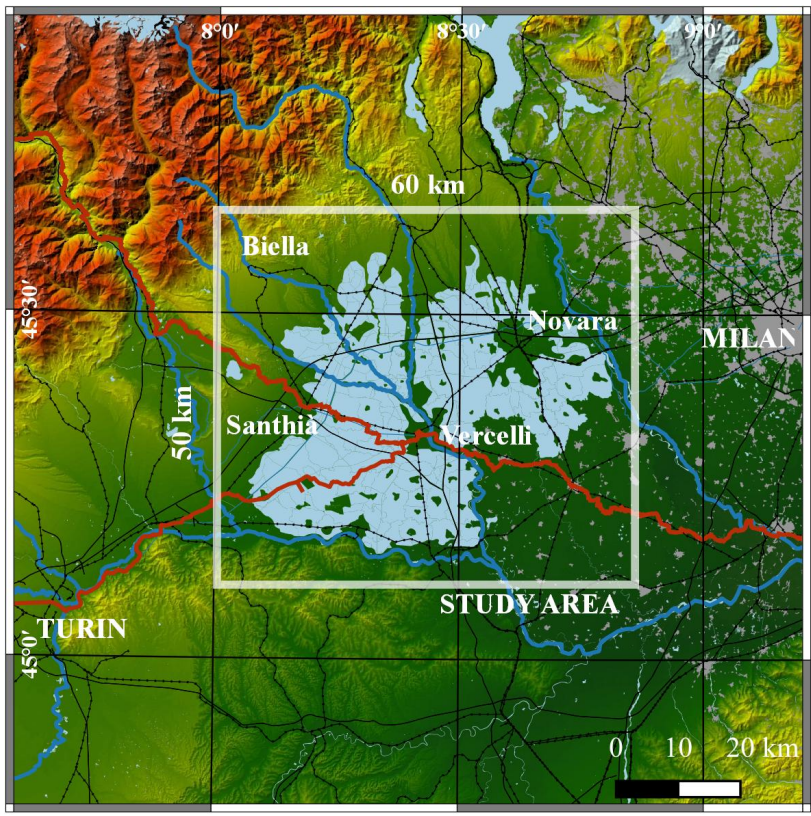

Study area: historical landscape of paddy-rice fields — Via Francigena

Figure 1. Map of the study area. The research refers to a flat landscape, surrounded by the Alps, in-between Turin and Milan. The area is characterized by large sections of paddy-rice fields which are crossed by the Via Francigena. The map shows the paddy-rice fields as it has been identified by the Piano Paesaggistico Regione Piemonte.

The landscape, which nowadays is still visible, is the result of a long process of stratification that can be dated back to the XII, when the Cistercian monks, coming from France, founded the Santa Maria di Lucedio Abbey near Vercelli and started the work of land reclamation in the northern area of Monferrato, in order to make lands cultivable. The monks introduced rice cultivation in the area and set up a network of farmhouses, named Grange, which supported the agricultural production in the area, over the centuries. The agricultural production was improved by the construction of an articulated network of canals, which catch the water from main rivers: Dora Baltea and Po, which flow from the Alps, and supply water for irrigation (Segre, 1983) (Monti, 2002). The historical network of the canals reached the peak of its extension in the XIX century, with the construction of the Cavour canal in 1866; extraordinary hydraulic work, which connects the Po river and the Ticino river, flowing in the opposite direction to the rivers that naturally come down from the mountains. The historical network of the canals has been extended step by step; the first stretch of Ivrea canal dates back to 1471 , the Cigliano canal dates back to 1785 , and the Depretis canal dates back to 1887 . The articulated network of the canals has been divided into smaller hydraulic works which supply water to the paddy-rice fields (Piano Paesaggistico Regionale, 2017). The agricultural landscape is also characterized by a system of historic farmhouses, which are scattered along the large sections of paddy-rice fields, organized with inner courtyard, even integrated with a chapel or watching towers. In terms of slow tourism, this area is characterized by a widespread local roads network, which enables the fruition of the agricultural landscape of paddy-rice fields. Within this network, it emerges the historical path of via Francigena, from Canterbury to Rome that, with one of its routes through Grand Saint Bernard and Aosta Valley, crosses the agricultural landscape from Santhià to Vercelli, west-east direction (Fig.1). In terms of slow tourism, it is a great resource for these territories; many pilgrims ride this path on foot or by bicycle and perceive the agricultural landscape of paddy-rice fields over the year. The local roads network, being used mainly for agricultural purposes, is well maintained and it has a great potential even for tourist fruition.

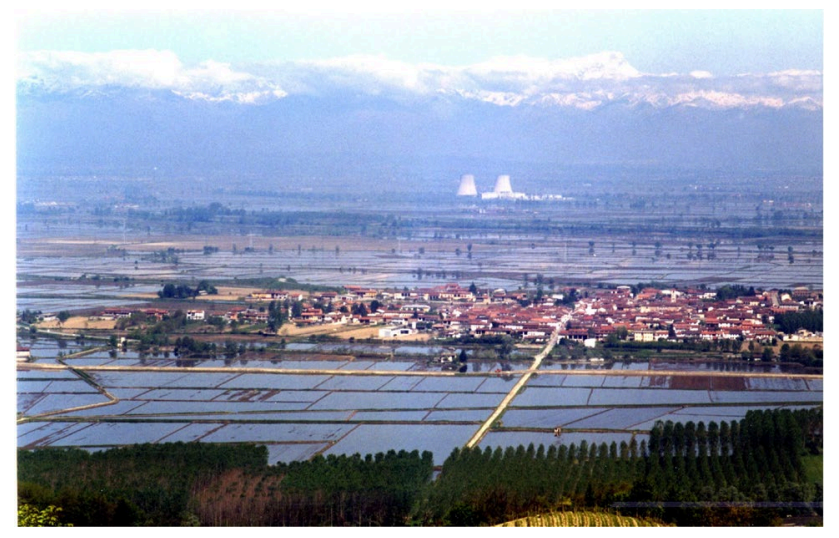

Figure 2. Scenic bird's eye view of the agricultural landscape during the period of flooding of paddy-rice fields.

\section{THE SEASONAL CONDITIONS OF PADDY-RICE FIELDS LANDSCAPE}

The changeable condition of the landscape, related to rice cultivation, is one the most distinctive feature of this historical agricultural landscape. The seasonal landscape changes are strongly interlaced with the annual cycle of the plants. Over the year, it can be perceived in different ways (Fig.3). In the winter season the soil appears completely bare, without plants; this is the stage of ploughing and levelling. Over the spring season, the flooding of paddy-rice fields occurs; this is the timing of seeding. The flowing of water in the fields is essential to protect the growing plants from thermal variations. This is a most delicate stage. From that, it is related the timing of the harvest. From the aesthetical point of view, this is the most attractive stage; paddy-rice fields are filled by water and the landscape appears as made by many small squares lakes. This appears as the clìmax condition of the landscape and most effectively expresses the relationships between natural factors (water availability, temperature, weather conditions) and the work of farmers which draw a new scenario year by year. After the flooding stage, during the summer, paddy-rice fields appear as green meadows: rice plants emerge from the soil with small green shoots and become higher and higher. In the autumn, the landscape looks like a mosaic of golden fields; this is the maturation and harvest stages, where the uniformity of the plants is kept under control. Mapping the variability of the historical agricultural landscape is a research topic, that can be 
investigated by exploiting the potential of time series of satellite high-resolution imagery and ground observations.

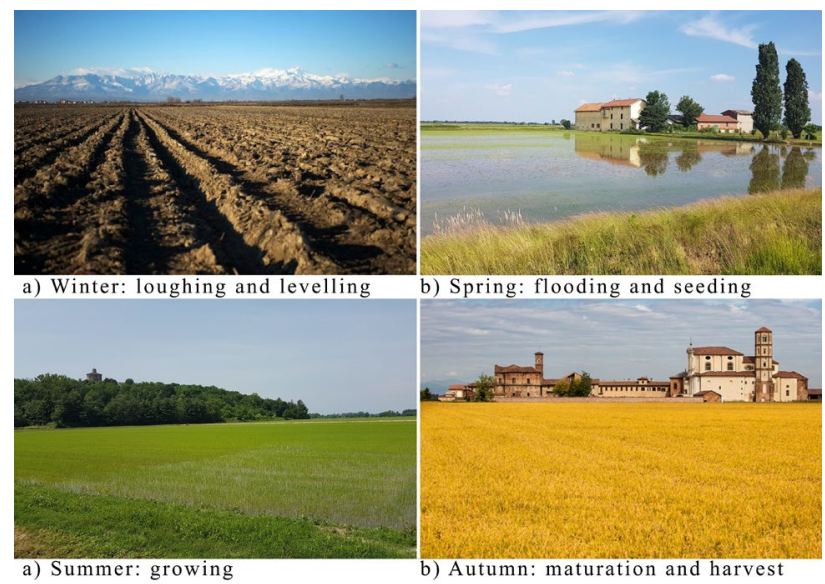

Figure 3. Different landscape conditions of the paddy-rice fields are taken over the seasons.

\section{MAPPING FLOODING OF PADDY-RICE FIELDS BY USING SENTINEL-2 SATELLITE IMAGERY}

One of the most attractive scenic condition of the historical landscape of paddy-rice fields is the flooding stage over the spring season (April and May). This section shows how to detect, on regional scale contexts, flooded paddy-rice fields by combining RS and GIS techniques. The Sentinel-2 mission comprises twin polar-orbiting satellites in the same orbit, phased at $180^{\circ}$ to each other. The Sentinel- 2 mission realized by ESA monitors variability in land surface conditions and support monitoring of changes to vegetation within growing season, by recording high-resolution multispectral imagery (image resolutions range within $10 \mathrm{~m}, 20 \mathrm{~m}$ and $60 \mathrm{~m}$ for single bands), (European Space Agency, 2015) (Fu et al., 2020). During the flooding period, the land surface of paddy-rice fields is a mixture of water and green rice plants, with water depths usually between 2 and $15 \mathrm{~cm}$ (Xiao et. al., 2006). Within the study area, it has been selected a path in the surrounding of Lucedio abbey, Leri Cavour farmhouse and Darola farmhouse, with the aim to observe the flooded paddy-rice fields (fig.4). Sentinel-2 satellite imagery have been used as data source for computing vegetation indices (VI), which are sensitive to vegetation changes. The current research explores the potential of NDVI (Normalized Difference Vegetation Index) for mapping the scenic condition of flooded paddy-rice fields. NDVI exploits the surface reflectance of near-infrared 785-899 $\mathrm{nm}$ and red $650-680 \mathrm{~nm}$; in the current research NDVI has been computed according to the following equation:

$$
\text { NDVI }=\frac{\text { B8 NIR }- \text { B4 Red }}{\text { B8 NIR }+ \text { B4 Red }}
$$

NDVI has been computed through GIS tools by using $10 \mathrm{~m}$ resolution imagery (NIR and Red bands). NDVI can range between -1 and +1 . The pixel-based recognition of the flooded paddy-rice fields has been conducted by using the following threshold: NDVI $<0$. The performed NDVI threshold enables detecting different typologies of water surfaces and other heterogeneous objects such as flooded paddy-rice fields, rivers, waterways, wetlands, permanent water bodies, and particular roofs in built-up areas. In order to isolate flooded paddy-rice fields in the map, it has been performed the mask processing by using open-access available vectorial datasets. The Sentinel-2 observation refers to the $24^{\text {th }}$ April 2021. The ground observation of the landscape has been conducted on $28^{\text {th }}$ April 2021, by recording georeferenced pictures and the GPS track of the survey, which enables the comparison between RS and ground observation (fig.5-6).

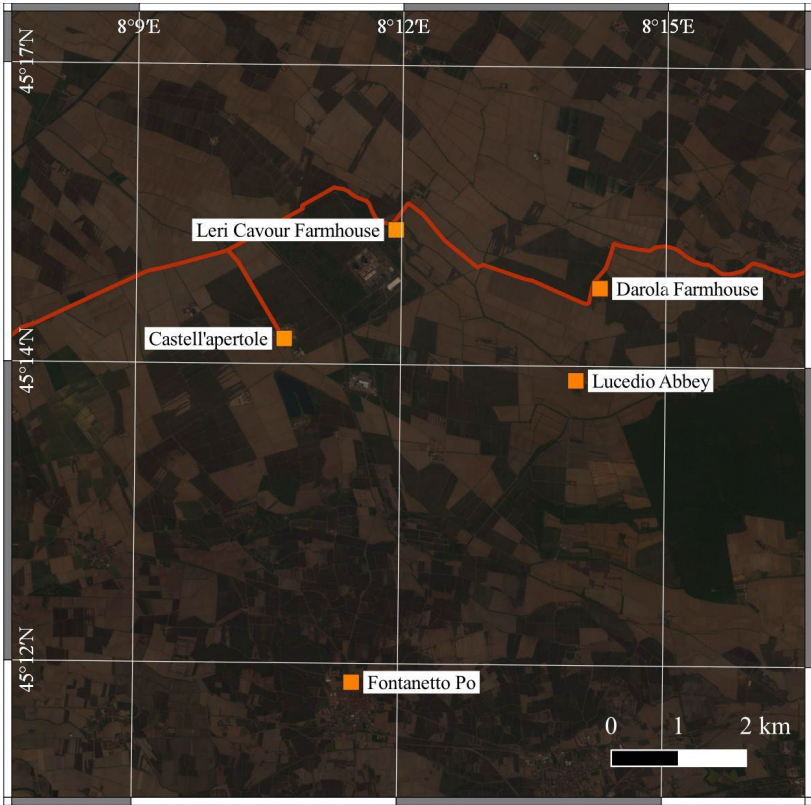

Points of interest $\longrightarrow$ Via Francigena

Figure 4. Satellite image of the area which has been selected for mapping the flooding of paddy-rice fields $24^{\text {th }}$ April 2021.

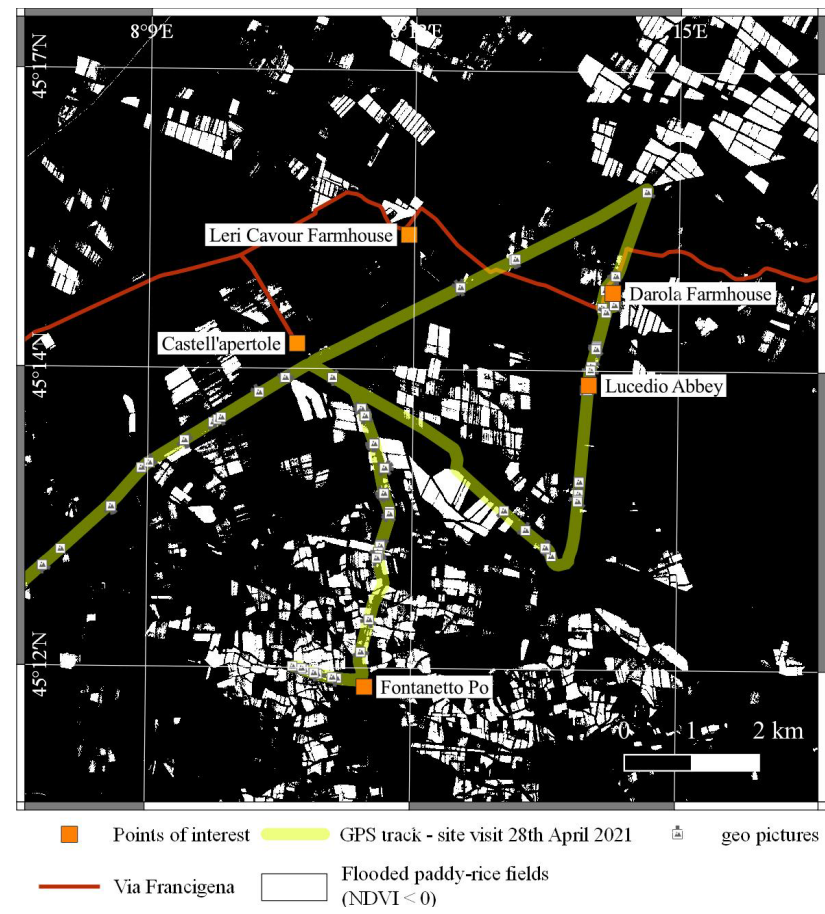

Figure 5. Mapping flooded paddy-rice fields by processing threshold NDVI $<0$. The map highlights the pictures taken along the ground observation, recorded by GPS track.

Sentinel-2 image $24^{\text {th }}$ April 2021 


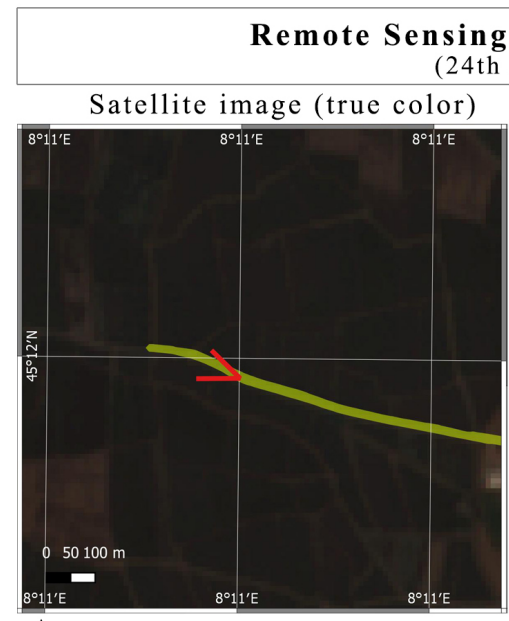

\section{pril 2021)}
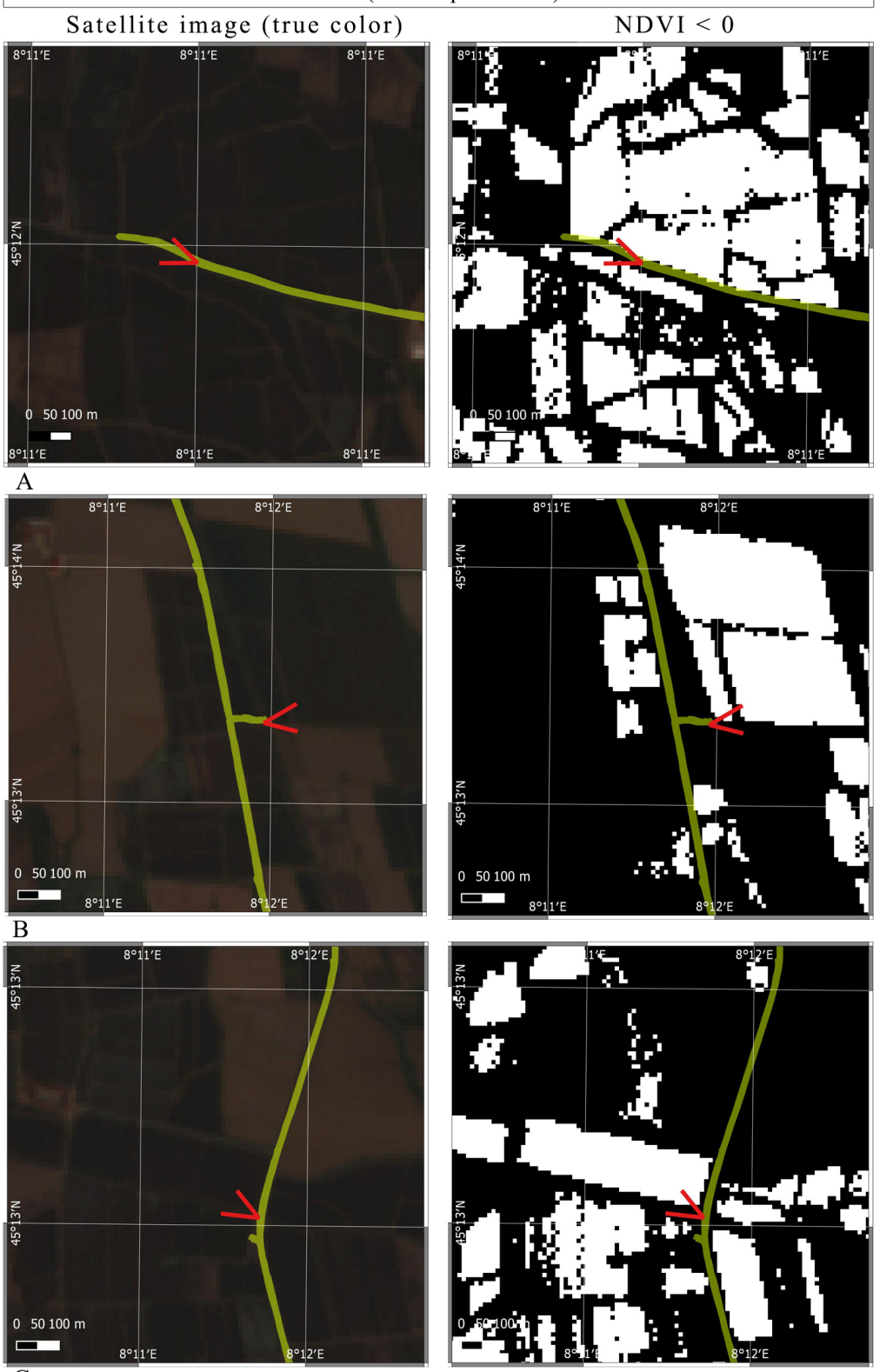

$\mathrm{C}$

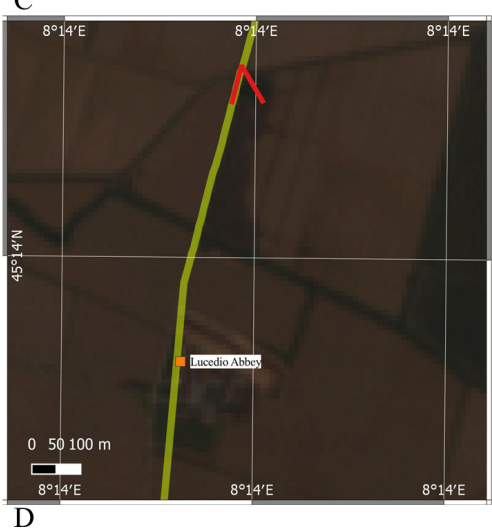

GPS track - ground observation
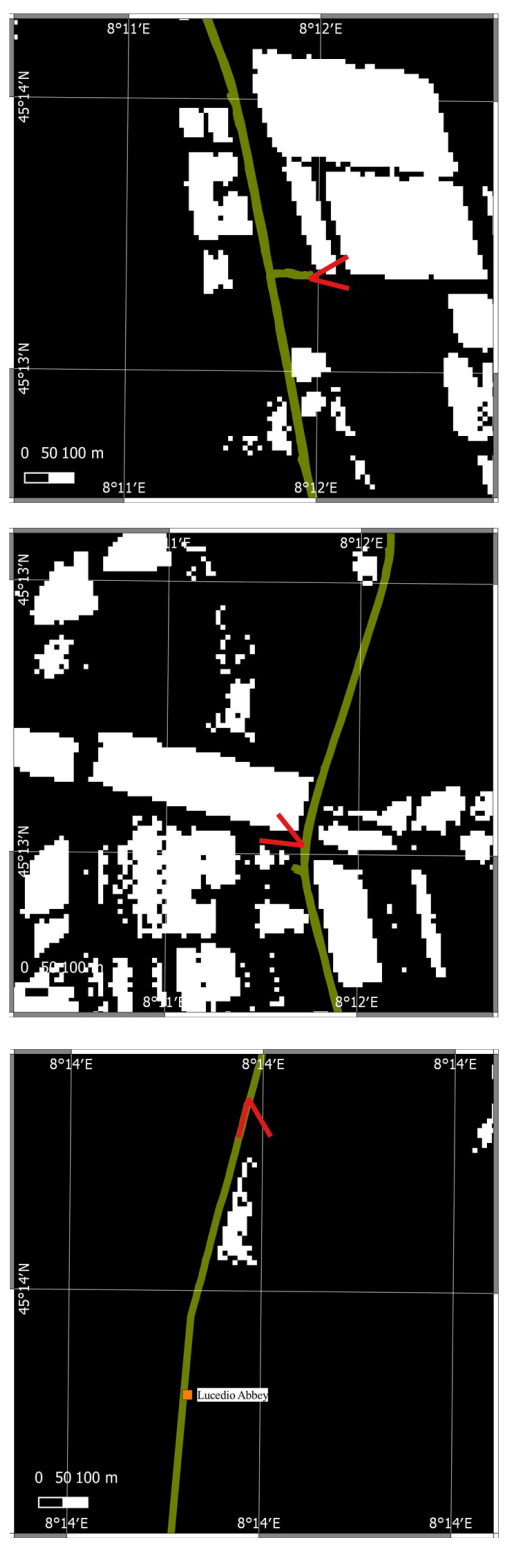

Flooded paddy-rice fields
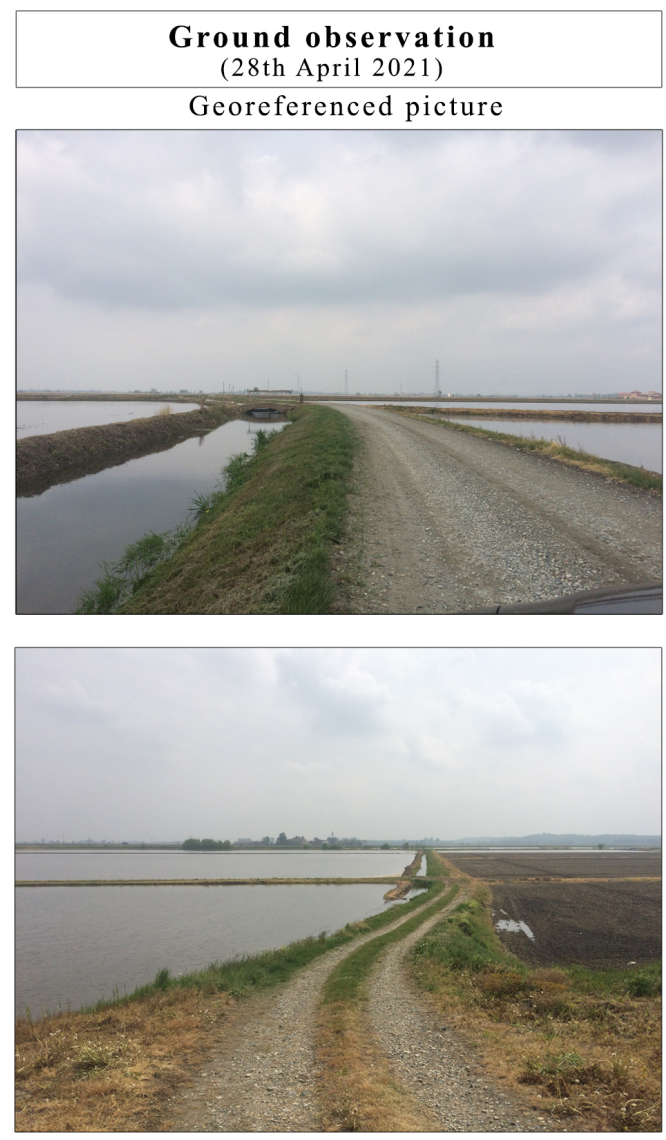
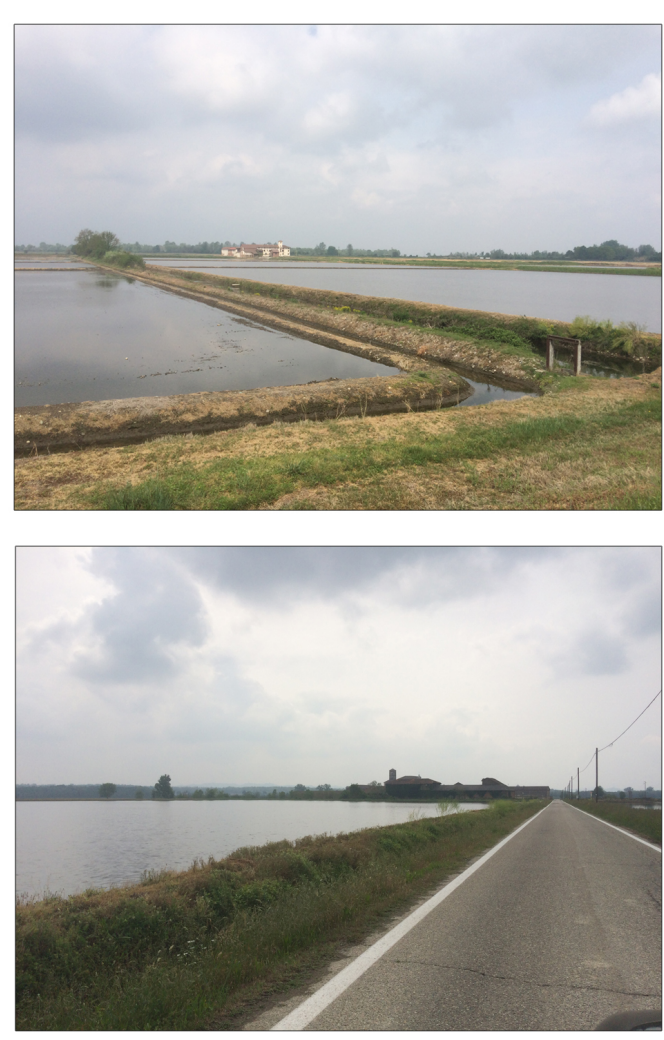

$\bigwedge$ Georeferenced pictures

Figure 6. Comparison between the pixel-based recognition method, based on Sentinel-2 imagery (24th April 2021) and ground observation (28 th April 2021). The abacus shows four different locations in the historical landscape of paddy-rice fields, selected in the survey. Although there are four days between the two observations, there is a good match between the two. 


\section{RESULTS}

In the field of slow tourism, it is still missing a tool capable of the map the scenic landscape conditions, which continuously change over the seasons. The research shows the effectiveness of the pixel-based recognition method for detecting flooded paddy-rice fields, which is confirmed by the ground observation survey. As it is visible in the previous image (Fig.6), there is a good match between the two typologies of observations. The first location (Fig. 6a) shows the stretch of a local road surrounded by flooded paddy-rice fields on both sides. This is one of the most scenic condition, where it seems to move between two flooded fields. On the NDVI map, it is visible the extension of flooded fields. The second location (Fig.6b) has been selected to check the effectiveness of the pixel-based recognition method. In fact, seeing the NDVI map, paddy-rice fields, which are located on the north, are flooded; on the contrary, the fields, which are located on the south, correspond to bare soils. This is also confirmed by the picture taken on the ground. The third location (Fig.6c) has been selected because there is a good match between the field on the north, which is completely flooded, and the picture. On the south, the fields are not completely flooded on the map. The picture on the ground was taken four days later; in fact, it shows the paddy-rice fields completely flooded. The difference between the two observations is probably due to the time elapsed (4 days), which was crucial to complete the flooding in the paddy-rice field. The fourth location (Fig.6d), on the north of Lucedio Abbey, was selected to show how time is a key factor to determine the precise correspondence between the satellite and ground observation. The NDVI map shows just a small area of the paddy-rice field covered by water. Instead, the picture taken on the ground (four days later) shows the paddy-rice field completely flooded. Even in this case the time elapsed between the two observations was a crucial factor.

\section{DISCUSSION}

The research shows the applicability of Sentinel-2 satellite images as data source for processing NDVI, that enables mapping of the flooded paddy-rice fields on large scale contexts. At mid-latitude, the Sentinel-2 data acquisition is 3 days. This is the time that can be used to reiterate the procedure and map the updated landscape conditions. However, it should be taken under consideration that satellite observations are not always available, due to bad weather conditions and cloud cover. As it is shown in the previous sections, ground observations are essential data source, to check the reliability of satellite observations, because they are more punctual and precise. Furthermore, ground observations are an alternative data source when satellite observations are not usable. In this sense, the monitoring of changeable conditions of the agricultural landscape can be also implemented by usergenerated content, which can be used as a complementary data source. New digital tools which are based on dynamic mapping could be developed to enrich the user's experience through the places.

\section{CONCLUSIONS}

Mapping seasonal conditions of the landscape is a very challenging topic, which may affect the tourism field. A dynamic global-scale map, showing where and when the flooding of the paddy-rice fields occurs, can become a tool to support a range of end-user decisions, but also new strategies for sustainable tourism planning.
The two main sources of information: one that we could define from outside, from the sky, that looks at phenomena from a distant point of view (satellite, map) and one generated from the inside, from the ground, that collects data and information directly from the earth (sensors, observation, experience) must find a common field of integration, so to produce a better knowledge of the landscape.

A more profound understanding of the processes that produce a landscape is generally important. In the specific case of the management of the paddy-rice fields it is crucial to understand how contemporary cultivation techniques (precision farming, data collection, satellite control and interpretation of the landscape) are able to keep into consideration also the historical value of the agricultural landscape as a wide natural, cultural, human asset (Sereni, 1961).

In this sense the information that define the landscape of the paddy-rice fields must result from the process of knowledge which is the result of three steps, between logical processes of analysis and synthesis: data collection, integrated interpretation of different sources to produce information, knowledge, to be made available both to outsiders (end-users, including tourists) and to insiders (inhabitants, farmers):

- $\quad$ interpretation of satellite images (thematic maps);

- $\quad$ interpretation of ground images (image segmentation);

- information collected by sensors;

- interpretation of shared information from social networks.

It is also important to consider that the use of digital techniques is today extended to multiple aspects of daily life, and thus plays a new and essential role, which surprisingly intertwines with nature, with the environment, with the territory, with history. In this sense, the digitization of the landscape also takes on a very special meaning. We must therefore consider the theatre of our life as a single interactive landscape, a device that is both natural and artificial, digital and complex, between history and the future, where the places and times of work (in this case agriculture) and leisure are blurred and where the boundaries between activities of production and the provision of services, between information, culture and knowledge, are increasingly blurred.

A smart land approach to agriculture is already becoming reality, through the more and more common use of precision farming techniques. On the other hand, that of a smart landscape is a broader concept that deserves a deeper implementation.

The access to digital processes requires broad band connection also in remote places, the nodes of the system must be fully integrated (internet of things applied to a more efficient management of the water resources), the farms can become digital nodes, places of knowledge, an up to date version of the old system of Grange the historical nodes of the medieval system that generated the landscape of today, merging knowledge and natural resources to create the landscape of the paddy-rice fields. 


\section{REFERENCES}

Chen, B., Qiu, Z., Nakamura, K., 2016. Tourist preferences for agricultural landscapes: a case study of terraced paddy fields in Noto Peninsula, Japan. Journal of Mountain Science, 13, 1880 1892. https://doi.org/10.1007/s11629-015-3564-0

Council of Europe, 2000. European Landscape convention and reference documents. https://rm.coe.int/european-landscapeconvention-book-text-feb-2008-en/16802f80c6.

Dong, J., Xiao, X., 2016. Evolution of regional to global paddy rice mapping methods: A review. ISPRS Journal of Photogrammetry and Remote Sensing, 119, 214-227. https://doi.org/10.1016/j.isprsjprs.2016.05.010.

European Space Agency 2015. Sentinel-2 User Handbook. Retrieved from:

https://earth.esa.int/documents/247904/685211/Sentinel-

2 User_Handbook

Fu, W., Ma, J., Chen, P., Chen, F., 2020. Remote Sensing Satellites for Digital Earth. In: Guo H., Goodchild M.F., Annoni A. (eds) Manual of Digital Earth. Springer, Singapore. https://doi.org/10.1007/978-981-32-9915-3_3

Jia, G., Zhang, L., Zhu, L., Xu, R., Liang, D., Xu, X., Bao, T., 2020, Digital Earth for Climate Change Research. In: Guo H., Goodchild M.F., Annoni A. (eds) Manual of Digital Earth. Springer, Singapore.

https://doi.org/10.1007/978-981-32-9915-3 14

Monti, P., 2002. Storie d'acqua. Le canalizzazioni del Vercellese e gli ecomusei del Piemonte. Pavone Canavese: Priuli \& Verlucca.

Regione Piemonte, 2017. Piano Paesaggistico Regionale, Schede degli ambiti di paesaggio.

Segre, L. 1983. Agricoltura e costruzione di un sistema idraulico nella pianura piemontese (1800-1880). Milano: BCI

Sereni, E., 1961. Storia del paesaggio agrario italiano, Roma, Biblioteca universale Laterza.

Xiao, X., Boles, S., Frolking, S., Salas, W. Moore III, B., Li, C., He, L., Zhao, R., 2002. Observation of flooding and rice transplanting of paddy rice fields at the site to landscape scales in China using VEGETATION sensor data, International Journal of Remote Sensing, 23:15, 3009-3022.

https://doi.org/10.1080/01431160110107734

Xiao, X., Boles, S., Frolking, S., Li, C.S., Babum J.Y., Salas, W, Moore, B., 2006. Mapping paddy rice agriculture in South and Southeast Asia using multi-temporal MODIS images. Remote Sensing of Environment, 100, 95-113. https://doi.org/10.1016/j.rse.2005.10.004

Fall Foliage prediction map. Retrieved from: https://smokymountains.com/fall-foliage-map/ 